\title{
Towards Figurative Expression Enhancement: Effects of the SVVR-Supported Worked Example Approach on the Descriptive Writing of Highly Engaged Students
}

\author{
Yi-Pin Huang 1ㅁ, Xiao-Li Zheng ${ }^{2, * \mathbb{C}}$, Chuang-Kai Chiu ${ }^{2}$, Jun Lei ${ }^{3}$, Gang Yang ${ }^{2}$, Hoisoo Kim ${ }^{1, *}$ \\ and Feng Wang $4, *$ (i)
}

check for

updates

Citation: Huang, Y.-P.; Zheng, X.-L.; Chiu, C.-K.; Lei, J.; Yang, G.; Kim, H.; Wang, F. Towards Figurative Expression Enhancement: Effects of the SVVR-Supported Worked Example Approach on the Descriptive Writing of Highly Engaged Students. Sustainability 2021, 13, 12260. https://doi.org/10.3390/ su132112260

Academic Editor: Attila Gere

Received: 15 October 2021

Accepted: 2 November 2021

Published: 6 November 2021

Publisher's Note: MDPI stays neutral with regard to jurisdictional claims in published maps and institutional affiliations.

Copyright: (c) 2021 by the authors. Licensee MDPI, Basel, Switzerland. This article is an open access article distributed under the terms and conditions of the Creative Commons Attribution (CC BY) license (https:/ / creativecommons.org/licenses/by/ $4.0 /)$.
1 Department of Education, Chonnam National University, Gwangiu 61186, Korea; hedy9409@gmail.com 2 Department of Educational Technology, Wenzhou University, Wenzhou 325035, China; 20170006@wzu.edu.cn (C.-K.C.); hnyg7906@163.com (G.Y.)

3 Wenzhou Experimental Primary School, Wenzhou 325088, China; Lj_801@163.com

4 Department of Electronics, Wenzhou University, Wenzhou 325035, China

* Correspondence: tilly222@163.com (X.-L.Z.); kimh@jnu.ac.kr (H.K.); wang_fengwf@163.com (F.W.); Tel.: +86-13456010451 (X.-L.Z.)

\begin{abstract}
During the past decades, many researchers have attempted to explore effective teaching methods for developing students' descriptive writing performance. In this study, the worked example was implemented as an effective way of guiding students to provide step-by-step solutions to learning tasks. Moreover, a spherical video-based virtual reality (SVVR) environment was provided to place students in real-world situations which enabled them to experience the learning contexts in depth. A pretest-posttest quasi experimental study was conducted to explore the influence of the SVVR-supported worked example approach and engagement level on students' Chinese descriptive writing performance. A total of 79 fourth-grade elementary school students participated in this study. The experimental group used SVVR with worked examples to complete Chinese writing assignments, whereas the control group used videos and worked examples. The results showed no significant effects of the SVVR-supported worked example approach compared with the conventional worked example approach regarding organization, sensory details, or creativity dimensions. As for the figurative expression dimension, students in the SVVR-supported worked example approach condition scored significantly higher. Moreover, high engagement students significantly outperformed low engagement students in all four writing performance dimensions. Additionally, a significant interaction effect between learning approach and engagement level on figurative expression was found.
\end{abstract}

Keywords: spherical video-based virtual reality; SVVR; technology-enhanced learning; experiential learning; worked example; engagement; descriptive writing performance

\section{Introduction}

With more than 6000 languages spoken around the world, language education is a way to break down linguistic and cultural boundaries in order to achieve a unified education for sustainable development [1,2]. In other words, sustainable development of individuals or society is likely to be unattainable without language education. It is acknowledged that native language learning precedes foreign language learning. To a large extent, the native language affects foreign language acquisition. Therefore, the acquisition of the native language is paramount. Language learning includes listening, speaking, reading, and writing. Among these, writing is an essential productive activity specifically for students because they use acquired language from class to write particular words for enunciating their emotions and viewpoints in order to achieve communicative goals [3,4]. Hence, writing skills are dispensable in language learning for academic achievement and for success at school and in professional life [5,6]. 
In the Chinese language curriculum, essay writing teaching is initiated in class from the third grade in elementary school, starting from descriptive article writing. This genre of writing requires the writer to describe a person, a place, a thing, or an event, giving multiple sensory details [7]. As we know, essay writing is considered as a complex and daunting task for students [8]. However, most teachers in China usually ask students to write essays out of class after elucidating lexical usage, rhetoric, structures, and main ideas of paragraphs from the appreciation perspective of an article in a textbook, with the intention of facilitating near transfer. Without internalization, for most students, near transfer is difficult to realize; therefore, Chinese elementary school students' written essays generally have low quality and tend to be mechanical, boring, fabricated, or disordered [8]. In some sense, the conventional worked example teaching without writing direction could not facilitate near transfer. According to Vygotsky [9], transfer cannot spontaneously occur; it needs a scaffold [10]. Previous studies have indicated that self-explanation prompts [11] and fading worked out steps [12] could promote near transfer performance [13].

From the perspective of experiential learning theory, students are immersed in a specific experience and develop new skills, attitudes, or ways of thinking through reflection on the experience [14]. In other words, to learn something new, it is better to actually have an experience. According to the standpoint of embodied cognition, human beings cannot experience the environment without their bodies. The body and its interactions with the environment play an important role in cognition [15]. In some sense, experiential learning enables learners to use their bodies to engage in cognitive processes while experiencing the environment. Previous studies have shown that bodily experience with appropriately designed instruction can have positive effects on learning outcomes [16-18]. Therefore, it is sine qua non for teachers to establish learning environments in which students can gain experience while learning. In this way, students learn more effectively when they are engaged in an experiential environment and reflect on their experiences.

Prensky stressed the significance of integrating technology into the teaching and learning process [19]. Numerous studies have also shown that technologies such as mobile technology, non-immersive virtual reality (VR), augmented reality (AR), and immersive virtual reality have the potential to facilitate learning by providing students with a better learning experience $[20,21]$. For instance, VR provides students with a real-world, interactive, and immersive educational environment that can support experiential learning [22-25], and which also enhances learning outcomes [26]. Especially, VR appears more beneficial for language learning [27-30]. However, normal VR requires high-level techniques and high cost, and it is hard to promote and adopt in schools [7]. To overcome these problems, Huang et al. [7] proposed the use of spherical video-based virtual reality (SVVR) to support Chinese students' writing activities; it is a novel technology with low-level techniques and low cost that also offers lifelike experiences. It has been demonstrated that VR/SVVR has the potential to improve performance as well as learning engagement [31,32].

With regard to engagement, many researchers have considered it as an outcome variable in order to confirm the effectiveness of VR/SVVR. However, it is worth mentioning that engagement level, as a crucial factor in the learning process, can be considered as one of the learner characteristics. This is because high engagement learners tend to be more actively involved in learning activities and more motivated to learn than low engagement learners [33,34]. One recent study indicated that, when students were supported by an SVVR learning system in writing activities, high engagement students outperformed low engagement students on descriptive writing performance in terms of structural integrity and language expression [32]. As a result, it is reasonable to set engagement level as one independent variable.

Therefore, in order to support students' writing activities, the SVVR-supported worked example approach was proposed in the present study. The worked example was implemented as an effective method of guiding students to provide step-by-step solutions to the learning tasks. In addition, the SVVR environment was provided to place students in real-world situations, enabling them to experience learning contexts in depth. 
A pretest-posttest quasi-experiment was conducted to investigate the effects of the proposed approach and engagement level on elementary school students' Chinese descriptive writing performance. The following research questions guided the study.

1. Does the SVVR-supported worked example approach significantly affect descriptive writing performance?

2. Does engagement level significantly influence descriptive writing performance?

3. Is there any interaction effect between learning approach and engagement level on descriptive writing performance?

\section{Theoretical Background}

Written language can be used for expressing one's opinions [35]. However, expressing one's opinions clearly and logically in written language is challenging. In educational settings, traditional teacher-centered pedagogies are often used to teach students to write; however, these pedagogies do not lead to the desired learning outcomes. In the past decades, learner-centered pedagogies, such as flipped learning [36,37], have been increasingly proposed. Experiential learning is also one of the learner-centered pedagogies. It emphasizes that individual experience performs the central role in the learning process. Kolb defined learning as "the process whereby knowledge is created through the transformation of experience. Knowledge results from the combination of grasping and transforming experience" (p. 41, [38]). Experiential learning consists of a four-stage learning cycle: concrete experience, reflective observation, abstract conceptualization, and active experimentation [38]. In other words, learners achieve effective learning when they progress through a four-stage cycle of (1) undergoing a concrete experience and (2) observing and reflecting on that experience, which leads to (3) forming abstract concepts, which are then (4) utilized in future situations to test hypotheses and generate new experiences. The aim of the first two is to grasp experience, while that of the latter two is to transform experience.

VR/ SVVR are promising technologies for implementing experiential learning activities. VR is a computer-generated, three-dimensional setting that produces a feeling of presence for users, as they explore a simulated environment [39,40]. The users can walk around, use various tools, and observe and interact with the virtual environment as if they are in a real place. Recently, VR has become a trendy technological application due to its three characteristics: immersion, imagination, and interactivity. According to the level of immersion, VR can be classified into three types: low-immersive, semi-immersive, and fully immersive VR. Low-immersive VR is desktop-based, while semi-immersive VR provides a partial virtual environment through graphical computing and large projector systems. Fully immersive VR requires the use of head-mounted devices [41]. Different VR technologies are utilized in various fields including entertainment, tourism, manufacturing, e-commerce, configuration, medicine, and education. In the field of medicine, some researchers have pointed out that VR can enhance neuroplasticity, referring to the ability of the nervous system to undergo physiological changes in response to genetic, behavioral, and environmental changes [42,43]. In educational contexts, VR offers very high potential to facilitate students' affective and cognitive learning outcomes [44]. Nevertheless, in conventional VR, the learning content should be developed using 3D animation technology, which requires high-level techniques and high cost in terms of time and money [7,45]. This is why there are difficulties promoting conventional VR in schools. As VR technology is evolving, however, SVVR (i.e., $360 \mathrm{VR}$ video) has emerged; it uses $360^{\circ}$ videos or photos to creative virtual environments [46]. SVVR has turned out to be a more prevalent tool with low-level techniques and a low development cost. In the last five years, SVVR has attracted interest from researchers in distinct domains, including business [47], classroom misbehavior management [45], science [48,49], physical geography [50], healthcare education [51], and sport [52].

Miscellaneous studies have employed VR technology to support the development of writing skills. Alpala and Peña [53] indicated that VR as a learning environment enriched students' vocabulary to express their ideas, engaged students in writing activities, and, 
in turn, shaped their writing skills. Patera et al. [28] investigated whether an interactive, semi-immersive Virtual Reality Environment (VRE) would raise motivation and stimulate pupils' imagination when they tried to finish a piece of imaginative writing in the English language learning tasks of elementary school. The findings were that VRE boosted students' motivation and primed their imagination. In another study, $\mathrm{Xu}$ et al. [54] conducted an experiment in which the treatment group produced their digital stories in Second Life while the control group produced their digital stories off-line. The experiment results indicated that the writing activity for digital storytelling in Second Life was beneficial in terms of boosting students' writing self-efficacy and enhancing their flow level.

More recently, an increasing number of studies have shown that applying SVVR would enhance students' language learning. Chen and Hwang [55] compared the interactive SVVR (ISVVR) approach with conventional multimedia for assisting the English speaking of EFL students with different cognitive styles: field dependent (FD) or field independent (FI). The findings revealed that FI learners gained more with the ISVVR learning approach regarding oral presentation than the FD learners. Furthermore, the ISVVR contributed more to reducing speaking anxiety and increasing learning motivation in FI learners than in FD learners. Chien et al. [56] proposed the peer-assessment-based SVVR approach to facilitate EFL students' English-speaking performance. The findings shed light on the positive effects of the proposed approach pertaining to the learners' English speaking, learning motivation, critical thinking skills, and decreasing their English learning anxiety. Concerning writing performance, Dolgunsöz et al. [57] integrated VR videos to support EFL students learning writing. In their study, VR videos were compared with traditional 2D videos. The findings indicated that VR experience did not significantly enhance students' short-term writing performance; however, VR videos were regarded to be encouraging in the long run based on delayed writing performance. Huang et al. [7] advocated using the SVVR approach to improve senior high school students' Chinese descriptive writing performance as to its content and appearance along with their creativity tendency and writing self-efficacy, as well as lowering their cognitive load. Similarly, Yang et al. [32] found that the SVVR learning system significantly influenced students' writing performance as concerns their thematic coherence, structural integrity, and linguistic expressiveness.

Based on the abovementioned research, previous studies have focused more on the superiority of VR/SVVR for facilitating writing performance, and less on learners' individual differences. Especially, less attention has been devoted to the writing performance of students considering their different levels of engagement. There are even no studies investigating the interaction effect between VR/SVVR and engagement level on writing performance. As previously highlighted, SVVR embeds $360^{\circ}$ spherical videos into the VR environment, which can enable learners to gain deep experience concerning the learning contexts [58] and can also help inspire their writing by providing them with a sensory experience of sound, color, and shape [59]. Therefore, it can be expected that students with the SVVR-supported worked example approach will significantly outperform those with the conventional worked example approach. Additionally, prior studies have demonstrated that engagement positively predicts learning achievement [60]. In other words, high engagement learners tend to be more actively involved in learning activities and more motivated to learn, and, in turn, gain more achievement than low engagement learners. Thus, it can be predicted that high engagement students will perform better than low engagement students. Furthermore, SVVR offers various immersive scenes, which requires students to actively engage in them. That is, SVVR may be more beneficial to high engagement students. Following this, this study aimed to address three hypotheses, which were:

Hypothesis 1 (H1). The students who learned with the SVVR-supported worked example approach will significantly outperform those who learned with the conventional worked example approach on descriptive writing performance. 
Hypothesis 2 (H2). The students with a high level of engagement will significantly outperform those with a low level of engagement on descriptive writing performance.

Hypothesis 3 (H3). There will be interaction effects between learning approach and engagement level on descriptive writing performance.

\section{The SVVR-Supported Worked Example Approach for Descriptive Article Writing}

In this study, the SVVR-supported worked example approach was employed to support students' Chinese descriptive article writing. An SVVR experience learning system was developed for engaging students in the undersea world. Inside the virtual environment, students were able to watch the $360^{\circ}$ videos through VR glasses to experience and explore the scene and listen to the narration of information about the undersea world, including swimming fish, coral reefs, and the like. Videos from the YouTube platform were used to develop the materials in this study. Two teachers with rich experience in Chinese writing instruction confirmed the suitability of the learning content in the learning environment. Furthermore, worked examples were presented by the teacher to teach students how to write a descriptive text step by step and what the indispensable components of a descriptive text are.

Figure 1 demonstrates the framework of the SVVR-supported worked example approach.

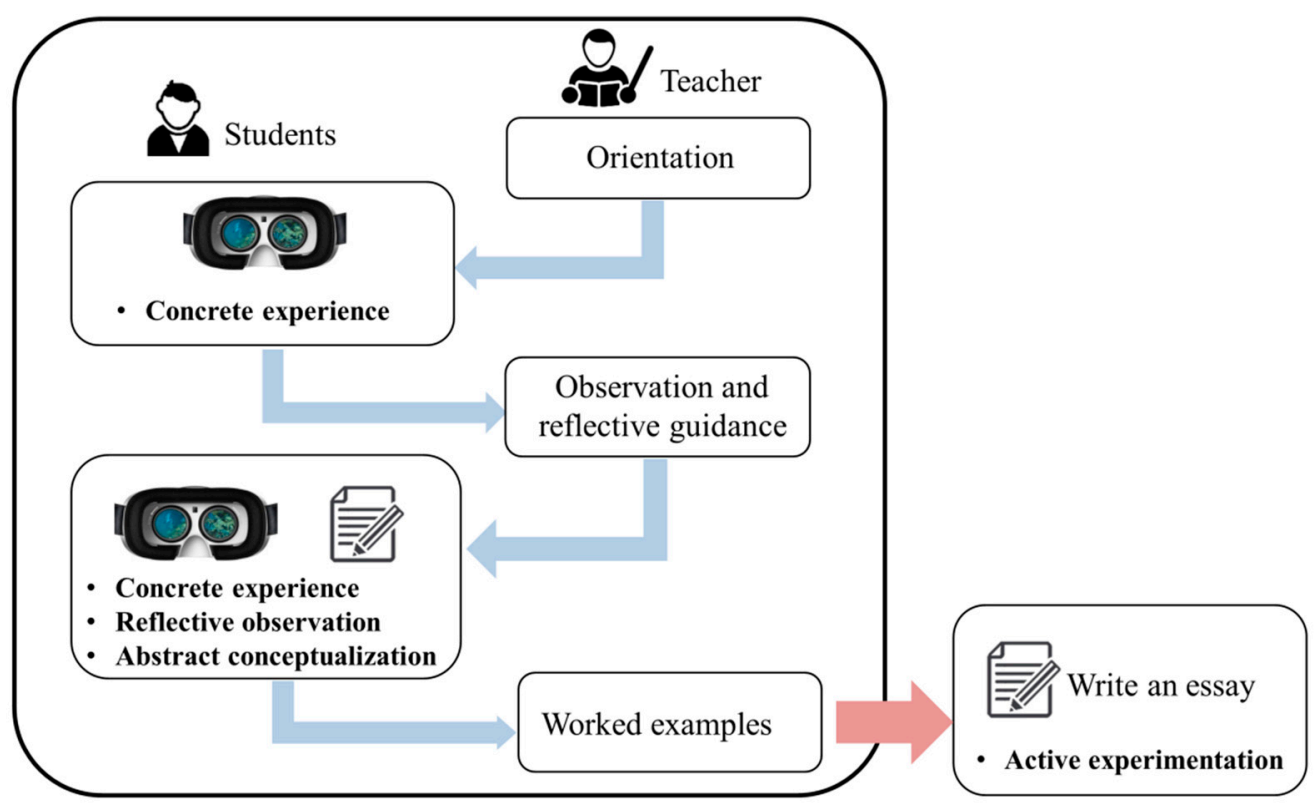

Figure 1. The framework of the SVVR-supported worked example approach.

The proposed learning approach was based on the experiential learning theory, which consists of four stages, namely concrete experience, reflective observation, abstract conceptualization, and active experimentation. The four-stage learning cycle was integrated into the framework of the SVVR-supported worked example approach.

In the first phase, the teacher introduced the writing task and helped students to become familiar with the SVVR system operation.

In the second phase, students were able to have the concrete experience of the undersea world by exploring spherical videos with the SVVR system. Figure 2 shows students using virtual glasses to experience the undersea world.

In the third phase, the teacher asked students what they saw inside the SVVR system. Then, the teacher provided the observation guidance, such as observing fish movement, object morphology, and reflective guidance, such as what these actions make students think of. 


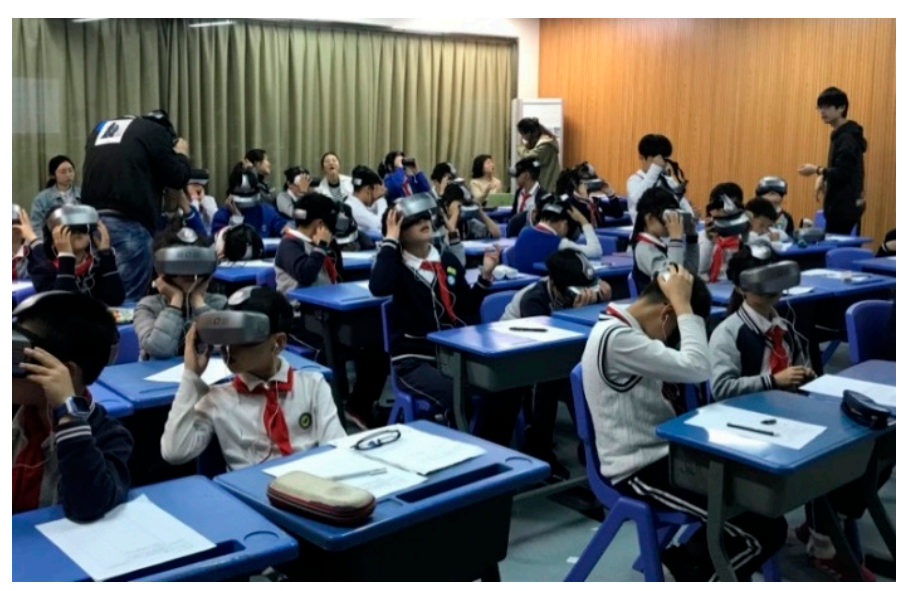

Figure 2. Writing instruction with SVVR.

In the fourth phase, with the help of observation guidance and reflective guidance, students were able to observe the undersea world and reflect on their experience. At the same time, students were provided with one worksheet on which they could write down their ideas with different descriptive words and sentences while exploring the undersea world. In this way, they could form new ideas or adjust their thoughts about the undersea world, gain writing inspiration, and form the initial structure of a writing framework in their minds.

In the fifth phase, the teacher provided the worked examples. That is, the different components of the descriptive article were presented to students step by step. In particular, the worked examples comprised typical patterns of high-quality descriptive articles. Through the teacher's explanations and elaborations, students could understand the main aspects of the descriptive article components. "White goose" was one of the worked examples. The article contained the introduction and body sections. In the introduction part, there was a strong thesis statement, which was "What a haughty animal." In the body part, three main aspects were focused on to discuss the goose's honking, movement, and eating in separate sections. Each aspect demonstrated how haughty the goose was.

Finally, the students were in the process of active experimentation. They were able to easily combine their knowledge with their undersea experience, internalize it into inspiration for writing a descriptive article, and organize their ideas to craft a descriptive article.

\section{Experiment Design}

\subsection{Participants}

The participants of this study were 79 fourth-grade students from two intact classes of an elementary school located in southern Zhejiang Province, China. The study was designed as a quasi-experiment, with the two classes randomly designated to either the experimental group or the control group. The experimental group included 38 students ( 21 boys and 17 girls) who learned with the SSVR and worked examples, while the remaining 41 (20 boys and 21 girls) adopted regular videos and worked examples. The same teacher guided the students with the same learning content in both groups, in order to avoid any other factor that may intervene during the experiment. None of the students had any previous experience of using SVVR in the Chinese writing classroom.

\subsection{Measurement Instruments}

\subsubsection{Rubric of Descriptive Writing Performance}

The rubrics of descriptive writing performance for Chinese elementary school students were developed based on the written composition scales proposed by Cheung et al. [61] and Yeung et al. [62], as well as the important components of descriptive writing raised by Yaacob and Suriyanti [63]. Then, a few adjustments were enacted, based on the suggestion of the Chinese teacher. 
The rubric includes four dimensions: organization, sensory details, figurative expression, and creativity, as shown in Table 1. Organization refers to the structure of the written composition. Sensory details indicate whether the written composition includes multiple and vivid sensory details that evoke the readers' senses of sight, sound, touch, smell, and taste. Figurative expression means whether students can use figurative language such as analogies, similes, metaphors, adjectives, and adverbs, etc., to describe the features of the subject. Creativity refers to creative and original ideas.

Table 1. Rubric for assessment of Chinese descriptive writing.

\begin{tabular}{|c|c|c|c|c|}
\hline Components & 4-Expert & 3-Practitioner & 2-Apprentice & 1-Novice \\
\hline Organization & $\begin{array}{l}\text { The structure of the written } \\
\text { composition is well } \\
\text { organized, coherent, and } \\
\text { thoughtful with a logical } \\
\text { and analytical progression } \\
\text { of ideas. }\end{array}$ & $\begin{array}{l}\text { The structure of the } \\
\text { written composition is } \\
\text { slightly loose. There is } \\
\text { some inconsistency but } \\
\text { the overall organization } \\
\text { is coherent. }\end{array}$ & $\begin{array}{l}\text { The structure of the } \\
\text { written composition is } \\
\text { simple. The } \\
\text { organization is } \\
\text { somewhat loose and } \\
\text { not coherent. }\end{array}$ & $\begin{array}{l}\text { The structure of the } \\
\text { written composition is } \\
\text { not clear with incorrect } \\
\text { paragraphing. }\end{array}$ \\
\hline Sensory details & $\begin{array}{l}\text { Accurately writes multiple } \\
\text { sensory details such as } \\
\text { sight, sound, touch, smell, } \\
\text { and taste. }\end{array}$ & $\begin{array}{l}\text { Appropriately writes } \\
\text { sensory details such as } \\
\text { sight, sound, touch, } \\
\text { smell, and taste. }\end{array}$ & $\begin{array}{l}\text { Attempts to write } \\
\text { sensory details such as } \\
\text { sight, sound, touch, } \\
\text { smell, and taste. }\end{array}$ & $\begin{array}{l}\text { Fails to write sensory } \\
\text { details such as sight, } \\
\text { sound, touch, smell, } \\
\text { and taste. }\end{array}$ \\
\hline $\begin{array}{l}\text { Figurative } \\
\text { expression }\end{array}$ & $\begin{array}{l}\text { Accurately uses various } \\
\text { analogies, similes, or } \\
\text { metaphors to describe the } \\
\text { features of the subject. }\end{array}$ & $\begin{array}{l}\text { Appropriately uses } \\
\text { several analogies, similes, } \\
\text { or metaphors to describe } \\
\text { the features of } \\
\text { the subject. }\end{array}$ & $\begin{array}{l}\text { Attempts to use several } \\
\text { analogies, similes, or } \\
\text { metaphors to describe } \\
\text { the features of } \\
\text { the subject. }\end{array}$ & $\begin{array}{l}\text { Fails to use or incorrectly } \\
\text { uses analogies, similes, or } \\
\text { metaphors to describe } \\
\text { the features of } \\
\text { the subject. }\end{array}$ \\
\hline Creativity & $\begin{array}{l}\text { Writes creative and } \\
\text { original ideas. }\end{array}$ & $\begin{array}{l}\text { Writes somewhat creative } \\
\text { and original ideas. }\end{array}$ & $\begin{array}{l}\text { Attempts to write } \\
\text { creative and } \\
\text { original ideas. }\end{array}$ & $\begin{array}{l}\text { Not able to write creative } \\
\text { and original ideas. }\end{array}$ \\
\hline
\end{tabular}

Each of these dimensions was scored on a scale of 1-4, ranging from "Novice" to "Expert." Spelling and punctuation errors were not penalized. The validity and reliability of this rubric were both confirmed. The validity was confirmed by the Delphi method. Furthermore, two experienced Chinese teachers rated the scores on the basis of the adopted rubrics in a double-blinded assessment mode. The inter-rater agreement coefficient was 0.87 , showing acceptable inter-rater reliability.

\subsubsection{Questionnaire of Engagement}

Students' engagement levels were measured based on the self-reported questionnaire developed by Skinner et al. [64]. The questionnaire was slightly revised to meet the needs of this study. Additionally, two experts checked the questionnaire to ensure the content validity and reliability. The questionnaire of engagement includes two dimensions: behavioral and emotional engagement. Behavioral engagement was assessed using five questions ( $\alpha=0.71$ in fall; $\alpha=0.72$ in spring), such as the item "When I'm in writing class, I listen very carefully". Emotional engagement was measured using five questions $(\alpha=0.83$ in fall; $\alpha=0.84$ in spring), such as the item "I enjoy learning new things in writing class". Each question was a five-point Likert item from " $1=$ Never" to " $5=$ Always". Thus, a total of 10 items with a maximum rating of 50 were used in this study for measuring student engagement. Moreover, engagement was divided into high and low engagement by the median of the engagement score. The alpha value of the questionnaire was 0.88 , which represents satisfactory internal consistency.

\subsection{Experimental Procedure}

Figure 3 reveals the experimental process of the study. Before the experiment, the students were required to write essays about the topic "My Favorite Animal" as a pre-test, 
and then to complete the self-report questionnaire regarding their engagement. To simplify the completion of the questionnaire for the students, the teacher read the questions aloud and made sure that the students selected the answers according to their thoughts.

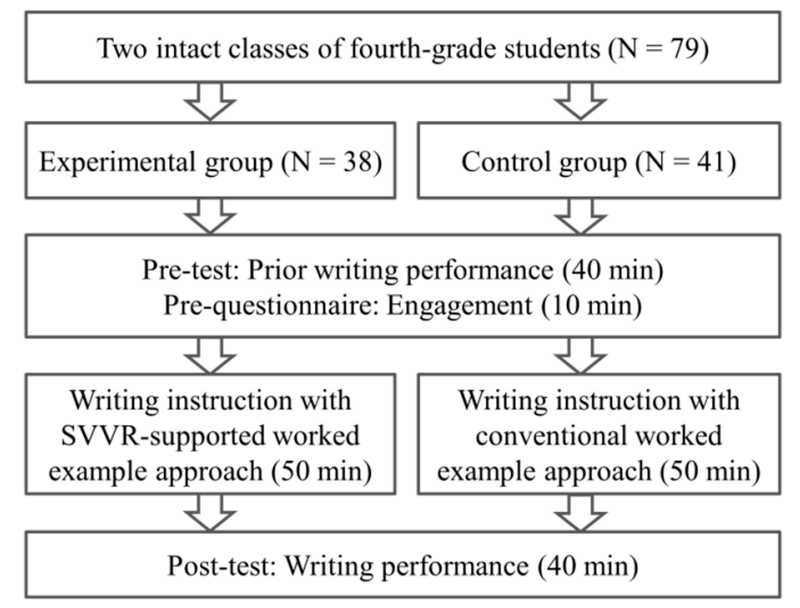

Figure 3. The experimental flow chart of the study.

In the learning process, the students observed the contexts in class. On the one hand, the experimental group students used SVVR to experience the undersea world. On the other hand, the teacher provided videos to the control group to show the contexts of the topic. Then, the teacher took worked examples to teach students how to write a descriptive text step by step in both groups. Various components of the descriptive article were illustrated by the teacher. Lastly, the students in the two groups wrote their own compositions about the "Undersea World" for the post-test. In this study, the experiment was administered within two weeks of April 2019. The pretests were conducted in the week before the experiment. In the spring semester of 2019, the experimental group experienced three contexts such as the Great Wall, the Forbidden City, and the Undersea World via SVVR, and the control group observed videos of the three contexts as above. The two groups, respectively, finished three descriptive compositions about the aforementioned three contexts. Each topic lasted for about 140 min within two weeks, including its own pretest, writing instruction, and posttest. This experiment was one of three topics.

\subsection{Statistical Analysis}

SPSS (V. 22.0) was used for quantitative data analysis. Consistently with the literature and current research goal, a pretest-posttest quasi experiment was implemented in which learning approach and engagement level were independent variables, the four dimensions (organization, sensory details, figurative expression, creativity) of writing performance were set as dependent variables, and prior writing performances were controlled as covariates.

Two-way analyses of covariance (ANCOVAs) were conducted in order to compare the writing performance in terms of four dimensions in the two different learning conditions (SVVR-supported worked example approach vs. conventional worked example approach) among elementary school students with different engagement levels (high vs. low). In all analyses, the significance level was set at 0.05 . Based on a partial $\eta^{2}$, the effect size was described as weak if between 0.01 and 0.05 , medium if between 0.06 and 0.14 , and large if above 0.14 [65].

\section{Results}

\subsection{Analysis of Organization}

Following verification that the assumption of homogeneity of regression was not violated $(F=1.47, p>0.05)$, a two-way ANCOVA was implemented using the pretest scores of organization as a covariate, the learning approach and the engagement level as 
independent variables, and the posttest scores of organization as the dependent variable. The pretest scores of organization showed that two groups were in a similar state at the time of the study $(F=0.91, p>0.05)$.

As demonstrated in Table 2, the two-way ANCOVA results showed that a significant main effect of engagement level was found $\left(F=6.84, p<0.05, \eta^{2}=0.09\right)$. However, the main effect of learning approach was not statistically significant $\left(F=3.30, p>0.05, \eta^{2}=0.04\right)$ and there was no significant interaction effect between independent variables on organization $\left(F=2.87, p>0.05, \eta^{2}=0.04\right)$.

Table 2. Results of two-way ANCOVA of students' organization.

\begin{tabular}{ccccccc}
\hline Source of Variation & SS & df & MS & $\boldsymbol{F}$ & $\boldsymbol{p}$ & $\boldsymbol{\eta}^{2}$ \\
\hline learning approach & 1.48 & 1 & 1.48 & 3.30 & 0.073 & 0.04 \\
engagement & 3.07 & 1 & 3.07 & $6.84 *$ & 0.011 & 0.09 \\
learning approach $\times$ engagement & 1.29 & 1 & 1.29 & 2.87 & 0.094 & 0.04 \\
$\quad$ error & 33.21 & 74 & 0.45 & & & \\
total & 945.00 & 79 & & & & \\
\hline to & & & & & &
\end{tabular}

Descriptive statistics of organization for each subgroup are shown in Table 3. Accordingly, students in the SVVR-supported worked example approach condition (adjusted mean $=3.52, S E=0.11$ ) did not significantly outperform those in the conventional worked example approach condition (adjusted mean $=3.24, S E=0.11$ ) on organization, regardless of their engagement levels. With respect to engagement level, the students' organization scores differed significantly; that is, the high engagement students (adjusted mean $=3.59$, $S E=0.11$ ) scored significantly higher on organization than the low engagement students (adjusted mean $=3.17$, SE $=0.11$ ).

Table 3. The descriptive data of the organization.

\begin{tabular}{ccccc}
\hline \multirow{2}{*}{ Condition } & \multirow{2}{*}{$\begin{array}{c}\text { Engagement } \\
\text { Level }(n)\end{array}$} & Pre-Test & \multicolumn{2}{c}{ Post-Test } \\
\cline { 3 - 5 } & low $(n=23)$ & $3.04(0.56)$ & $3.09(0.79)$ & $3.16(0.15)$ \\
\hline \multirow{2}{*}{$\begin{array}{c}\text { Video + worked } \\
\text { example }\end{array}$} & high $(n=18)$ & $3.67(0.49)$ & $3.39(0.70)$ & $3.33(0.16)$ \\
& total $(n=41)$ & $3.32(0.61)$ & $3.22(0.76)$ & $3.24(0.11)$ \\
\hline \multirow{2}{*}{ SVVR + worked } & low $(n=18)$ & $3.33(0.59)$ & $3.17(0.79)$ & $3.18(0.16)$ \\
example & high $(n=20)$ & $3.55(0.60)$ & $3.90(0.31)$ & $3.86(0.15)$ \\
& total $(n=38)$ & $3.45(0.60)$ & $3.55(0.69)$ & $3.52(0.11)$ \\
\hline \multirow{2}{*}{ total } & low $(n=41)$ & $3.17(0.59)$ & $3.12(0.78)$ & $3.17(0.11)$ \\
& high $(n=38)$ & $3.61(0.55)$ & $3.66(0.58)$ & $3.59(0.11)$ \\
\hline & total $(n=79)$ & $3.38(0.61)$ & $3.38(0.74)$ & \\
\hline
\end{tabular}

\subsection{Analysis of Sensory Details}

A two-way ANCOVA was conducted to analyze the difference in sensory details. The pretest scores of sensory details were set as the covariate, the learning approach and engagement level were the independent variables, and the posttest scores of sensory details were the dependent variable. The assumption of homogeneity of regression was satisfied $(F=0.03, p>0.05)$. Moreover, the ANOVA results did not show any significant difference in the pretest scores of sensory details between the experimental group and the control group $(F=1.26, p>0.05)$; that is, both groups had similar levels in the sensory details dimension.

As shown in Table 4, the ANCOVA results indicated that there was a statistically significant main effect of engagement level $\left(F=4.76, p<0.05, \eta^{2}=0.06\right)$ on students' writing performance in terms of sensory details. However, the main effect of the learning approach was not statistically significant $\left(F=3.32, p>0.05, \eta^{2}=0.04\right)$ and there was no 
significant interaction effect between learning approach and engagement level on sensory details $\left(F=3.91, p>0.05, \eta^{2}=0.05\right)$.

Table 4. Results of two-way ANCOVA of students' sensory details.

\begin{tabular}{ccccccc}
\hline Source of Variation & SS & df & MS & $\boldsymbol{F}$ & $p$ & $\boldsymbol{\eta}^{2}$ \\
\hline learning approach & 1.81 & 1 & 1.81 & 3.32 & 0.072 & 0.04 \\
engagement & 2.59 & 1 & 2.59 & $4.76^{*}$ & 0.032 & 0.06 \\
learning approach $\times$ engagement & 2.13 & 1 & 2.13 & 3.91 & 0.052 & 0.05 \\
$\quad$ error & 40.27 & 74 & 0.54 & & & \\
total & 452.00 & 79 & & & & \\
& & & & & &
\end{tabular}

Table 5 shows the descriptive data of the sensory details for each subgroup. In terms of learning approach, students (adjusted mean $=2.41, S E=0.12$ ) who used the SVVRsupported worked example approach did not obtain significantly higher scores than those (adjusted mean $=2.10, S E=0.12$ ) who used the conventional worked example approach. In comparison with high engagement students (adjusted mean $=2.44, S E=0.12$ ), the posttest scores of sensory details of the low engagement students (adjusted mean $=2.07, S E=0.12$ ) were significantly lower than those of the students with a high engagement level.

Table 5. The descriptive data of the sensory details.

\begin{tabular}{|c|c|c|c|c|}
\hline \multirow{2}{*}{ Condition } & \multirow{2}{*}{$\begin{array}{l}\text { Engagement } \\
\text { level }(n)\end{array}$} & \multirow{2}{*}{$\begin{array}{l}\text { Pre-Test } \\
M(S D)\end{array}$} & \multicolumn{2}{|c|}{ Post-Test } \\
\hline & & & $M(S D)$ & Adjusted Mean (SE) \\
\hline \multirow{3}{*}{$\begin{array}{c}\text { Video + worked } \\
\text { example }\end{array}$} & low $(n=23)$ & $1.96(0.82)$ & $2.04(0.88)$ & $2.08(0.15)$ \\
\hline & $\operatorname{high}(n=18)$ & $2.44(0.86)$ & $2.22(0.65)$ & $2.12(0.18)$ \\
\hline & total $(n=41)$ & $2.17(0.86)$ & $2.12(0.78)$ & $2.10(0.12)$ \\
\hline \multirow{3}{*}{$\begin{array}{c}\text { SVVR + worked } \\
\text { example }\end{array}$} & low $(n=18)$ & $1.89(0.68)$ & $2.00(0.84)$ & $2.05(0.18)$ \\
\hline & $\operatorname{high}(n=20)$ & $2.05(0.69)$ & $2.75(0.64)$ & $2.76(0.17)$ \\
\hline & total $(n=38)$ & $1.97(0.68)$ & $2.40(0.82)$ & $2.41(0.12)$ \\
\hline \multirow{3}{*}{ total } & low $(n=41)$ & $1.93(0.75)$ & $2.02(0.85)$ & $2.07(0.12)$ \\
\hline & high $(n=38)$ & $2.24(0.79)$ & $2.50(0.69)$ & $2.44(0.12)$ \\
\hline & total $(n=79)$ & $2.08(0.78)$ & $2.25(0.81)$ & \\
\hline
\end{tabular}

\subsection{Analysis of Figurative Expression}

A two-way ANCOVA was adopted to investigate the scores of figurative expression. The assumption of homogeneity of regression revealed that the assumption was satisfied $(F=0.86, p>0.05)$. The pretest scores of figurative expression did not yield a significant difference between the experimental group and the control group $(F=2.46, p>0.05)$, indicating that the students of both groups had equivalent prior writing performance in terms of figurative expression.

As demonstrated in Table 6, the results indicated that significant main effects of both learning approach $\left(F=4.86, p<0.05, \eta^{2}=0.06\right)$ and engagement level $(F=8.71$, $p<0.01, \eta^{2}=0.11$ ) were found. Furthermore, a significant effect was also proved for the interaction between the independent variables $\left(F=7.07, p<0.05, \eta^{2}=0.09\right)$ on students' figurative expression.

A simple main effect analysis was implemented to investigate the influences of the learning approach on figurative expression of the students with different engagement levels. 
Table 6. Results of two-way ANCOVA of students' figurative expression.

\begin{tabular}{ccccccc}
\hline Source of Variation & SS & df & MS & $\boldsymbol{F}$ & $p$ & $\boldsymbol{\eta}^{2}$ \\
\hline learning approach & 2.88 & 1 & 2.88 & $4.86^{*}$ & 0.031 & 0.06 \\
engagement & 5.16 & 1 & 5.16 & $8.71^{* *}$ & 0.004 & 0.11 \\
learning approach $\times$ engagement & 4.18 & 1 & 4.18 & $7.07^{*}$ & 0.010 & 0.09 \\
error & 43.81 & 74 & 0.59 & & & \\
total & 340.00 & 79 & & & & \\
${ }^{*} p<0.05,{ }^{* *} p<0.01$. & & & & &
\end{tabular}

Tables 7 and 8 show the descriptive data of the figurative expression and the results of simple main effects, respectively. Figure 4 displays the interaction between the learning approach and the engagement level on figurative expression. It illustrates that, for low engagement students, the conventional worked example approach (adjusted mean $=1.63$, $S E=0.16)$ was better than the SVVR-supported worked example approach (adjusted mean $=1.56, S E=0.19)$ on their posttest scores of figurative expression; however, there was no significant difference $(F=0.22, p>0.05)$. For high engagement students, students (adjusted mean $=2.57, S E=0.17$ ) who studied with the SVVR-supported worked example approach significantly outdid those who studied with the conventional worked example approach (adjusted mean $=1.72, S E=0.19)(F=7.24, p<0.05)$.

Table 7. The descriptive data of the figurative expression.

\begin{tabular}{ccccc}
\hline \multirow{2}{*}{ Condition } & Engagement & Pre-Test & \multicolumn{2}{c}{ Post-Test } \\
\cline { 3 - 5 } & Level $(n)$ & $\boldsymbol{M}($ SD) & $\boldsymbol{M}($ SD) & Adjusted Mean $($ SE) \\
\hline \multirow{2}{*}{ video + worked } & low $(n=23)$ & $1.61(0.78)$ & $1.61(0.58)$ & $1.63(0.16)$ \\
example & $\operatorname{high}(n=18)$ & $2.11(0.76)$ & $1.83(0.86)$ & $1.72(0.19)$ \\
& total $(n=41)$ & $1.83(0.80)$ & $1.71(0.72)$ & $1.67(0.12)$ \\
SVVR + worked & low $(n=18)$ & $1.28(0.46)$ & $1.44(0.51)$ & $1.56(0.19)$ \\
example & high $(n=20)$ & $1.80(0.89)$ & $2.60(1.10)$ & $2.57(0.17)$ \\
& total $(n=38)$ & $1.55(0.76)$ & $2.05(1.04)$ & $2.07(0.13)$ \\
total & low $(n=41)$ & $1.46(0.67)$ & $1.54(0.55)$ & $1.60(0.13)$ \\
& high $(n=38)$ & $1.95(0.84)$ & $2.24(1.05)$ & $2.14(0.13)$ \\
& total $(n=79)$ & $1.70(0.79)$ & $1.87(0.90)$ & \\
\hline
\end{tabular}

Table 8. The analysis of simple main effects.

\begin{tabular}{|c|c|c|c|c|c|}
\hline Source of Variation & SS & df & MS & $F$ & $p$ \\
\hline learning approach & & & & & \\
\hline learning approach @ low engagement & 0.06 & 1 & 0.06 & 0.22 & 0.640 \\
\hline $\begin{array}{c}\text { learning approach @ high engagement } \\
\text { engagement }\end{array}$ & 6.81 & 1 & 6.81 & $7.24 *$ & 0.011 \\
\hline engagement @ video + worked example & 0.001 & 1 & 0.00 & 0.00 & 0.953 \\
\hline engagement@ @VVR + worked example & 9.99 & 1 & 9.99 & $12.95 * *$ & 0.001 \\
\hline
\end{tabular}

As for students who studied with the conventional worked example approach, there was no significant difference between high engagement students (adjusted mean $=1.72$, $S E=0.19$ ) and low engagement students (adjusted mean $=1.63, S E=0.16$ ), with $F=0.00$ $(p>0.05)$. However, in the SVVR-supported worked example approach condition, the engagement level had a significant influence on students' figurative expression $(F=12.95$, $p<0.01$ ). In other words, high engagement students (adjusted mean $=2.57, S E=0.17$ ) significantly outperformed low engagement students (adjusted mean $=1.56, S E=0.19$ ) on their scores of figurative expression with the SVVR-supported worked example approach. 


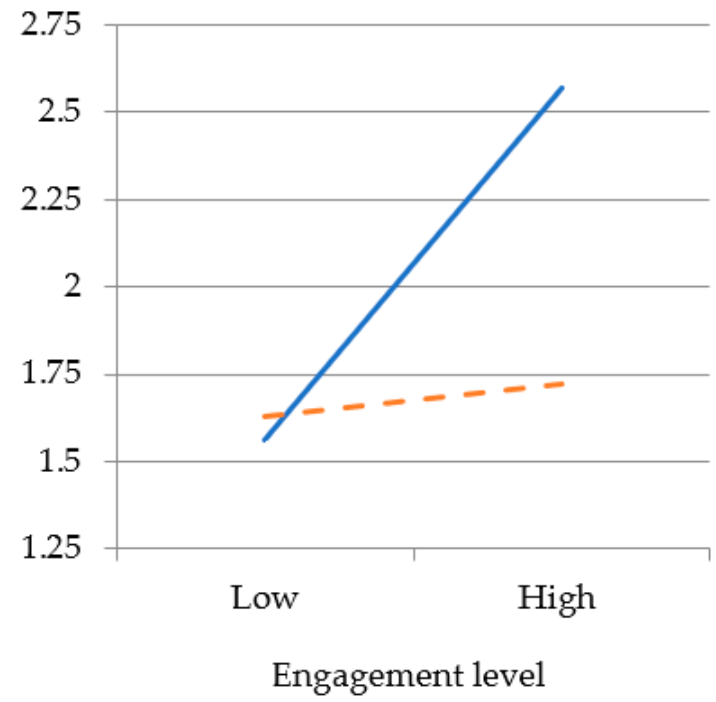

Learning approach

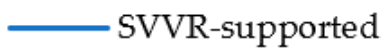
worked example approach

- - - conventional worked example approach

Figure 4. Interaction between learning approach and engagement level for figurative expression.

\subsection{Analysis of Creativity}

After checking that the assumption of homogeneity of regression was not violated $(F=0.00, p>0.05)$, the creativity scores were analyzed with the two-way ANCOVA. The pretest showed that both groups had a similar level of creativity $(F=0.16, p>0.05)$.

As illustrated in Table 9, the ANCOVA results indicated that the main effect of the learning approach was not statistically significant $\left(F=0.13, p>0.05, \eta^{2}=0.00\right)$ and that there was no significant interaction effect between the two interventions $(F=1.35, p>0.05$, $\left.\eta^{2}=0.02\right)$. However, a significant effect was confirmed for the engagement level ( $F=9.91$, $p<0.01, \eta^{2}=0.12$ ) on students' creativity.

Table 9. Results of two-way ANCOVA of students' creativity.

\begin{tabular}{ccccccc}
\hline Source of Variation & SS & df & MS & $\boldsymbol{F}$ & $\boldsymbol{p}$ & $\boldsymbol{\eta}^{2}$ \\
\hline learning approach & 0.07 & 1 & 0.07 & 0.13 & 0.725 & 0.00 \\
engagement & 5.43 & 1 & 5.43 & $9.91^{* *}$ & 0.002 & 0.12 \\
learning approach $\times$ engagement & 0.74 & 1 & 0.74 & 1.35 & 0.250 & 0.02 \\
error & 40.59 & 74 & 0.55 & & & \\
total & 375.00 & 79 & & & & \\
\hline (**
\end{tabular}

According to the descriptive data on the posttest scores of creativity, as shown in Table 10, students who learned with the SVVR-supported worked example approach (adjusted mean $=2.05, S E=0.12$ ) did not perform significantly better than those who learned with the conventional worked example approach (adjusted mean $=1.99, S E=0.12$ ) in terms of creativity. Moreover, the high engagement students (adjusted mean $=2.29, S E=0.12$ ) had better scores on creativity than the low engagement students did (adjusted mean $=1.74$, $S E=0.12)$. 
Table 10. The descriptive data of creativity.

\begin{tabular}{|c|c|c|c|c|}
\hline \multirow{2}{*}{ Condition } & \multirow{2}{*}{$\begin{array}{c}\text { Engagement } \\
\text { Level }(n)\end{array}$} & \multirow{2}{*}{$\begin{array}{c}\text { Pre-Test } \\
M(S D)\end{array}$} & \multicolumn{2}{|c|}{ Post-Test } \\
\hline & & & $M(S D)$ & Adjusted Mean (SE) \\
\hline \multirow{3}{*}{$\begin{array}{l}\text { video + worked } \\
\text { example }\end{array}$} & low $(n=23)$ & $1.70(0.82)$ & $1.74(0.75)$ & $1.81(0.16)$ \\
\hline & $\operatorname{high}(n=18)$ & $2.33(0.91)$ & $2.28(0.89)$ & $2.16(0.18)$ \\
\hline & total $(n=41)$ & $1.98(0.91)$ & $1.98(0.85)$ & $1.99(0.12)$ \\
\hline \multirow{3}{*}{$\begin{array}{l}\text { SVVR + worked } \\
\text { example }\end{array}$} & low $(n=18)$ & $1.72(0.83)$ & $1.61(0.50)$ & $1.67(0.18)$ \\
\hline & high $(n=20)$ & $2.05(0.89)$ & $2.45(0.89)$ & $2.42(0.17)$ \\
\hline & total $(n=38)$ & $1.90(0.86)$ & $2.05(0.84)$ & $2.05(0.12)$ \\
\hline \multirow{3}{*}{ total } & low $(n=41)$ & $1.71(0.81)$ & $1.68(0.65)$ & $1.74(0.12)$ \\
\hline & high $(n=38)$ & $2.18(0.90)$ & $2.37(0.88)$ & $2.29(0.12)$ \\
\hline & total $(n=79)$ & $1.94(0.88)$ & $2.01(0.84)$ & \\
\hline
\end{tabular}

\subsection{Comparison of Two Samples from Two Different Groups}

One sample of written compositions was selected from each group, as shown in Figure $5 a, b$. In terms of organization, both samples consisted of introduction, body, and conclusion sections. For sample EG, the student used the sentence "Many people will ask me what kind of world is under the sea. Then I will answer, the undersea world is wonderful and magical" in both the introduction and conclusion sections, to clearly emphasize the beauty and magic of the undersea world. In the body, the student described the sea turtle and manta rays in detail, starting each paragraph with the sentence "Look, there is a huge turtle swimming here" and "Yo! Here are two manta rays swimming towards us," respectively. As for the sample CG, the student wrote "A group of cute creatures hide under the blue sea" as the introduction. Subsequently, various characteristics of sea turtles were specifically described. However, the paragraphing was relatively logical. In the conclusion, the student wrote "This is the wonderful undersea world" to express his affection. In short, the structure of the sample EG was well organized, coherent, and considerate with logical and analytical improvements of ideas, while the structure of the sample CG was slightly loose and somehow inconsistent; however, the overall organization was good enough.

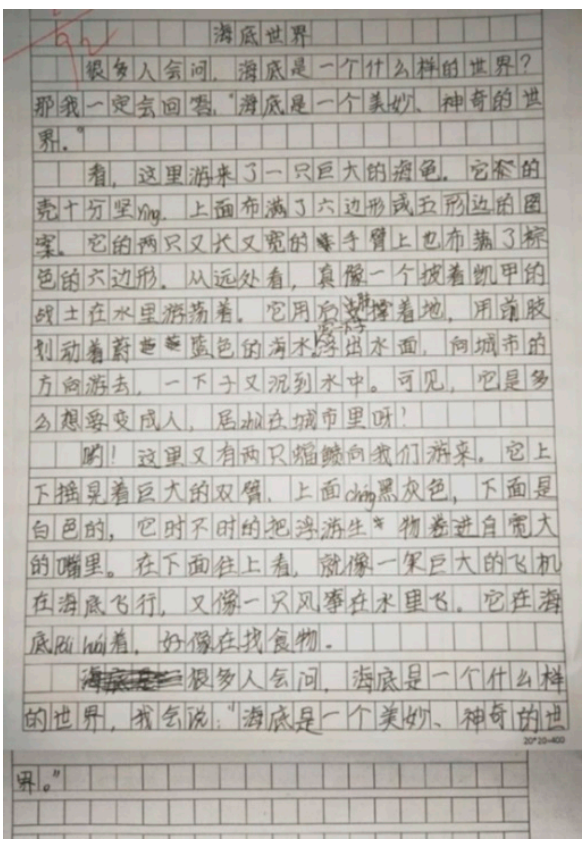

(a)

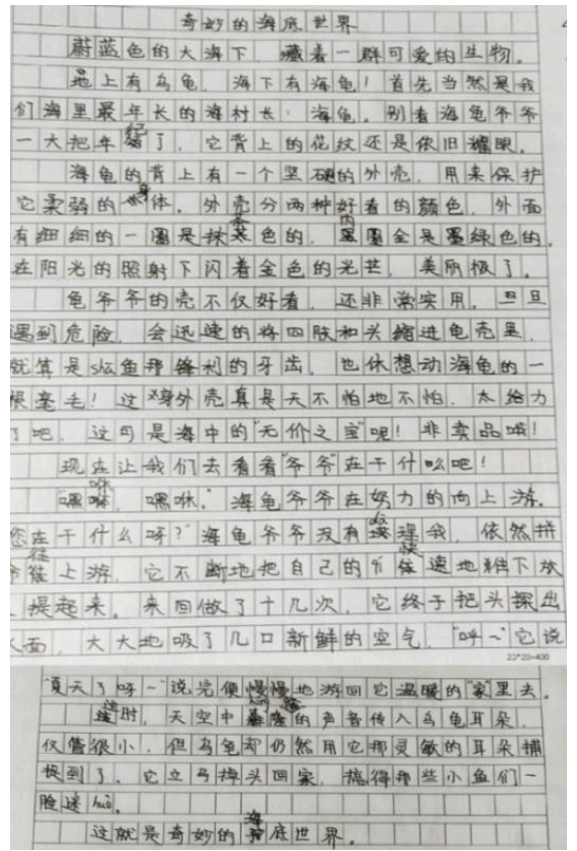

(b)

Figure 5. (a) Sample from the experimental group; (b) sample from the control group. 
Pertaining to the sensory details of the written compositions, both students used vocabulary that mainly described sight. On the one hand, in the sample EG, the student described the sea turtle's shell (i.e., "Its shell is very hard, covered with hexagonal or pentagonal patterns"), flippers (i.e., "Its two long and wide 'arms' are also covered with brown hexagons"), and movement (i.e., "It supports the ground with its hind limbs and strokes the blue water with its forelimbs. It surfaces, swimming towards the city, and then sinks again"). Moreover, the student depicted the manta rays' flippers and eating (i.e., "It shakes its huge 'arms' up and down. The upper part is black-gray and the lower part is white. From time to time, it rolls plankton into its wide mouth"). In the sample CG, on the other hand, the student wrote the features and function of the sea turtle's shell, and also the movement of the sea turtle, which were "The shell is divided into two beautiful colors, the outer circle is matcha color, and the inner circle is dark green", "In case of danger, it will quickly retract its limbs and head into the turtle shell", "It keeps putting its flippers down quickly and then lifting them up, doing this more than a dozen times, then finally puts its head out of the water and takes a few breaths of fresh air". Compared to the sample EG, the sample CG also contained details about sound, "At this time, the rumbling sound in the sky reaches the turtle's ears ......"

With regard to figurative expression, the sample EG included many examples of figurative language to describe the features of the subject, such as "From a distance, it looks like a warrior in armor wandering in the water", "Looking up from below, it looks like a huge airplane flying under the sea, and like a kite flying in the water" and so on. As for the sample CG, the student only used personification to depict the features of the sea turtle. The student called the sea turtle "Grandpa Turtle".

With respect to creativity, both students wrote somewhat creative and original ideas.

\section{Discussion}

The purpose of this study was to examine how SVVR combined with worked examples would benefit writing performance while considering the students' engagement level. The experiment was conducted by using a non-equivalent quasi-experimental design in which learning approach and engagement level were the independent variables, and the dependent variables were four dimensions of writing performance, namely, organization, sensory details, figurative expression, and creativity. On the basis of the findings, the hypotheses can be analyzed as follows.

\subsection{Effects of the SVVR-Supported Worked Example Approach}

The experimental results partially supported Hypothesis 1 . It was found that the students using the SVVR-supported worked example approach did not significantly outperform those using the conventional worked example approach on writing performance in terms of organization, sensory details, and creativity. The failure to find a significant difference between the different learning approaches may be due to the fact that the SVVR did not improve learning outcomes in the short term [57], and even though SVVR provided an immersive environment for the students, they might be more interested in the new medium rather than in the writing task, as Styati [66] mentioned in his research. Another reason why SVVR provided no advantage over the video is that worked examples might play a more important role than SVVR did. If this were the case, the worked examples in both conditions would have eliminated the relative advantage of SVVR. In this study, both SVVR and the video assisted the students in writing their essays, and then the worked examples showed a description of the steps of how to write a descriptive text. Paas et al. [67] stated that worked examples decrease the learning-task-related cognitive load through three steps: reducing the cognitive load via intrinsic load with the existence of a few schemas; minimizing the extraneous load by scaffolding; promoting the germane load when self-regulation occurs. Thus, the worked example effect as the instructional principle in writing activities would make students in both groups able to decrease their cognitive load related with the writing tasks. On the other hand, with the SVVR-supported 
worked example approach, students had significantly better figurative expression than those of the conventional worked example approach. Figurative expression means that students use figurative language to express their complex emotional experiences [68]. In other words, the use of figurative expression is inseparable from individual experience. SVVR allows students to locate somewhere they have not been before, and to be exposed to events they might not otherwise encounter. In addition, SVVR enables students to observe their surroundings in an authentic-like context. Thus, this experimental finding can be interpreted to mean that embodied experiential learning using SVVR can facilitate students' description of their experiences in a figurative way.

\subsection{Effects of Engagement Level}

The experimental findings supported Hypothesis 2. In other words, high engagement students always significantly outperformed low engagement students in all four dimensions of writing performance, regardless of the different learning approaches. Engagement involves active and deep involvement, commitment, and concentration, which all contradict shallow participation and lack of attention [69]. The students who engaged more in the task tended to be actively involved in writing instruction and paid more attention to writing. Conversely, the low engagement students did not make an effort to participate, and they lacked interest. Engagement results in students' achievement gain and contributes to their motivational, cognitive, and behavioral development [33,70-72]. Thus, the results showed that high engagement led to high writing performance, and low engagement led to low writing performance. It is likely that engagement also has an effect on students performance in any topic that is learned. Educators or teachers should be aware of students' different engagement levels and should take them into consideration when they are engaged in other activities.

\subsection{Interaction Effects between the Learning Approach and Engagement Level}

The experimental results also partially supported Hypothesis 3 . The results indicated that the interaction effects between two independent variables were not significant for organization, sensory details, or creativity. However, the interaction effect was found in the figurative expression dimension. For students with low engagement, the two different learning approaches did not show any difference in figurative expression. However, for high engagement students, the SVVR-supported worked example approach significantly improved their figurative expression scores compared with the conventional worked example approach. Accordingly, it meant that high engagement learners benefited more from the SVVR-supported worked example approach in the experiential learning context. Engagement is a psychological set of processes which refers to the behavioral, as well as the emotional, efforts that the student spends in order to seek new information and develop it into meaningful knowledge [73]. That is, high engagement learners tended to involve their behavioral and emotional engagement in the SVVR-based learning environment to perform the figurative expression more successfully.

\section{Conclusions}

In sum, the SVVR-supported worked example approach significantly contributed to one dimension, that is, figurative expression, but not other dimensions, that is, organization, sensory details, and creativity of writing performance. This is consistent with the statement that developing students' writing skills is a challenging job and students require sufficient time to improve their writing capabilities [74]. Besides, when educators try to integrate SVVR technology into writing instruction, the engagement is an influential factor in students' writing performance. For maximizing the effectiveness of SVVR, it is equally essential to explore the factors that promote engagement.

There are some limitations for interpretation of the experimental results that should be noted. The study was conducted over a short period of time. The generalization of the effects should be examined by enacting a long-term experiment. Furthermore, the results 
presented in this study are based on two groups of students who were taught Chinese writing lessons using different learning approaches, which means that the evidence is highly situated in the selected tasks and groups. Future studies are needed to determine if the effects of the SVVR-supported worked example approach would play different roles in writing performance for older students. For example, without considering engagement levels, middle or high school students may benefit more from the SVVR-supported worked example approach than upper elementary school students. Nevertheless, we believe that, in further research, this experiment can be repeated with different wider samples. In addition, it would be fruitful to explore the effects of learning approach and engagement level on students' other abilities in different activities. Furthermore, since we speculate that the worked example played a more important role in both groups than the educational technology did, future research exploring whether the presence/absence of worked examples would yield a main effect is needed. Last but not the least, more promising technologies should be explored to assist language teaching and learning for the sake of education sustainability.

Author Contributions: Conceptualization, X.-L.Z. and G.Y.; methodology, X.-L.Z., J.L. and F.W.; software, C.-K.C.; validation, X.-L.Z., G.Y. and H.K.; formal analysis, Y.-P.H.; investigation, J.L.; resources, C.-K.C.; data curation, X.-L.Z.; writing—original draft preparation, Y.-P.H.; writingreview and editing, X.-L.Z. and F.W.; visualization, Y.-P.H.; supervision, H.K.; project administration, X.-L.Z.; funding acquisition, X.-L.Z. All authors have read and agreed to the published version of the manuscript.

Funding: This research was funded by the Department of Education of Zhejiang Province of the People's Republic of China, grant number Y201839174.

Institutional Review Board Statement: This study was conducted according to the approval of Research Ethics Review Committee of Department of Educational Technology, College of Education, Wenzhou University with approval number RERCET-2020-0410A-WZUCE.

Informed Consent Statement: Informed consent was obtained from all subjects involved in the study.

Data Availability Statement: The data can be obtained by sending request e-mails to the corresponding author.

Acknowledgments: We thank the Chinese teachers from Wenzhou Experimental Primary School who provided participants for this study, and the internship students from Wenzhou University who gave writing lessons to participants according to the instructional design provided by the research team.

Conflicts of Interest: The authors declare no conflict of interest.

\section{References}

1. Ter Horst, E.E.; Pearce, J.M. Foreign languages and sustainability: Addressing the connections, communities, and comparisons standards in higher education. Foreign Lang. Ann. 2010, 43, 365-383. [CrossRef]

2. Cai, J.-Y.; Wang, R.-F.; Wang, C.-Y.; Ye, X.-D.; Li, X.-Z. The influence of learners' cognitive style and testing environment supported by virtual reality on English-speaking learning achievement. Sustainability 2021, 13, 11751. [CrossRef]

3. Wang, Y.-H. Exploring the effectiveness of integrating augmented reality-based materials to support writing activities. Comput. Educ. 2017, 113, 162-176. [CrossRef]

4. Tse, S.-K.; Hui, S.-Y. Chinese writing curriculum reforms in Hong Kong in recent years and their impact on teaching and learning. Read. Writ. 2016, 29, 1013-1037. [CrossRef]

5. Beam, S.; Williams, C. Technology-mediated writing instruction in the early literacy program: Perils, procedures, and possibilities. Comput. Sch. 2015, 32, 260-277. [CrossRef]

6. Hussin, S.; Abdullah, M.Y.; Ismail, N.; Yoke, S.K. The effects of CMC applications on ESL writing anxiety among postgraduate students. Engl. Lang. Teach. 2015, 8, 167-172. [CrossRef]

7. Huang, H.-L.; Hwang, G.-J.; Chang, C.-Y. Learning to be a writer: A spherical video-based virtual reality approach to supporting descriptive article writing in high school Chinese courses. Br. J. Educ. Technol. 2020, 51, 1386-1405. [CrossRef]

8. $\mathrm{Li}, \mathrm{X}$;; Chu, S.K.W. Using design-based research methodology to develop a pedagogy for teaching and learning of Chinese writing with wiki among Chinese upper primary school students. Comput. Educ. 2018, 126, 359-375. [CrossRef] 
9. Vyotsky, L. Mind in Society: The Development of Higher Psychological Processes; Harvard University Press: Cambridge, MA, USA, 1978.

10. Mortazavi, M.; Jafarigohar, M.; Roohi, A. Can scaffolding mechanisms of structuring and problematizing facilitate the transfer of genre-based knowledge to another discourse mode? J. Teach. Lang. Skills 2017, 35, 133-156.

11. Rittle-Johnson, B. Promoting transfer: Effects of self-explanation and direct instruction. Child Dev. 2006, 77, 1-15. [CrossRef] [PubMed]

12. Renkl, A.; Atkinson, R.K.; Große, C.S. How fading worked solution steps works-A cognitive load perspective. Instr. Sci. 2004, 32, 59-82. [CrossRef]

13. Atkinson, R.K.; Renkl, A.; Merrill, M.M. Transitioning from studying examples to solving problems: Effects of self-explanation prompts and fading worked-out steps. J. Educ. Psychol. 2003, 95, 774-783. [CrossRef]

14. Lewis, L.H.; Williams, C.J. Experiential learning: Past and present. In New Directions for Adult and Continuing Education; Jackson, L., Caffarella, R.S., Eds.; Jossey-Bass: San Francisco, CA, USA, 1994; pp. 5-16.

15. Gibbs, R. Embodiment and Cognitive Science; Cambridge University Press: New York, NY, USA, 2005.

16. Antle, A.N.; Corness, G.; Droumeva, M. What the body knows: Exploring the benefits of embodied metaphors in hybrid physical digital environments. Interact. Comput. 2009, 21, 66-75. [CrossRef]

17. Fischer, U.; Moeller, K.; Bientzle, M.; Cress, U.; Nuerk, H.C. Sensori-motor spatial training of number magnitude representation. Psychon. Bull. Rev. 2011, 18, 177-183. [CrossRef]

18. Zhou, J. The effects of reciprocal imitation on teacher-student relationships and student learning outcomes. Mind Brain Educ. 2012, 6, 66-73. [CrossRef]

19. Prensky, M. Digital natives, digital immigrants part 1. On Horizon 2001, 9, 1-6. [CrossRef]

20. Cheng, S.-C.; Hwang, G.-J.; Chen, C.-H. From reflective observation to active learning: A mobile experiential learning approach for environmental science education. Br. J. Educ. Technol. 2019, 50, 2251-2270. [CrossRef]

21. Huang, X.; Zou, D.; Cheng, G.; Xie, H. A systematic review of AR and VR enhanced language learning. Sustainability 2021, 13, 4639. [CrossRef]

22. Aiello, P.; D’Elia, F.; Di Tore, S.; Sibilio, M. A constructivist approach to virtual reality for experiential learning. E-Learn. Digit. Media 2012, 9, 317-324. [CrossRef]

23. Jarmon, L.; Traphagan, T.; Mayrath, M.; Trivedi, A. Virtual world teaching, experiential learning, and assessment: An interdisciplinary communication course in Second Life. Comput. Educ. 2009, 53, 169-182. [CrossRef]

24. Kwon, C. Verification of the possibility and effectiveness of experiential learning using HMD-based immersive VR technologies Virtual Real. 2019, 23, 101-118. [CrossRef]

25. Su, C.-H.; Cheng, T.-W. A sustainability innovation experiential learning model for virtual reality chemistry laboratory: An empirical study with PLS-SEM and IPMA. Sustainability 2019, 11, 1027. [CrossRef]

26. Merchant, Z.; Goetz, E.T.; Cifuentes, L.; Keeney-Kennicutt, W.; Davis, T.J. Effectiveness of virtual reality-based instruction on students' learning outcomes in K-12 and higher education: A meta-analysis. Comput. Educ. 2014, 70, 29-40. [CrossRef]

27. Lloyd, A.; Rogerson, S.; Stead, G. Imagining the potential for using virtual reality technologies in language learning. In Digital Language Learning and Teaching: Research, Theory, and Practice; Carrier, M., Damerow, R.M., Bailey, K.M., Eds.; Routledge: New York, NY, USA, 2017; pp. 222-234.

28. Patera, M.; Draper, S.; Naef, M. Exploring magic cottage: A virtual reality environment for stimulating children's imaginative writing. Interact. Learn. Environ. 2008, 16, 245-263. [CrossRef]

29. Shadiev, R.; Yang, M. Review of studies on technology-enhanced language learning and teaching. Sustainability 2020, $12,524$. [CrossRef]

30. Yang, J.C.; Chen, C.H.; Jeng, M.C. Integrating video-capture virtual reality technology into a physically interactive learning environment for English learning. Comput. Educ. 2010, 55, 1346-1356. [CrossRef]

31. Allcoat, D.; von Mühlenen, A. Learning in virtual reality: Effects on performance, emotion and engagement. Res. Learn. Technol. 2018, 26, 1-13. [CrossRef]

32. Yang, G.; Chen, Y.-T.; Zheng, X.-I.; Hwang, G.-J. From experiencing to expressing: A virtual reality approach to facilitating pupils' descriptive paper writing performance and learning behavior engagement. Br. J. Educ. Technol. 2021, 52, 807-823. [CrossRef]

33. Fredricks, J.A.; Blumenfeld, P.C.; Paris, A.H. School engagement: Potential of the concept, state of the evidence. Rev. Educ. Res. 2004, 74, 59-109. [CrossRef]

34. Furrer, C.; Skinner, E. Sense of relatedness as a factor in children's academic engagement and performance. J. Educ. Psychol. 2003, 95, 148-162. [CrossRef]

35. Grljević, O.; Bošnjak, Z.; Kovačević, A. Opinion mining in higher education: A corpus-based approach. Enterp. Inf. Syst. 2020, 1-26. [CrossRef]

36. Liu, C.K. A holistic approach to flipped classroom: A conceptual framework using e-platform. Int. J. Eng. Bus. Manag. 2019, 11, 1-9. [CrossRef]

37. Challob, A.I. The effect of flipped learning on EFL students' writing performance, autonomy, and motivation. Educ. Inf. Technol. 2021, 26, 3743-3769. [CrossRef]

38. Kolb, D.A. Experiential Learning: Experience as the Source of Learning and Development; Prentice-Hall: Englewood Cliffs, NJ, USA, 1984. 
39. Lee, E.A.-L.; Wong, K.W. Learning with desktop virtual reality: Low spatial ability learners are more positively affected. Comput. Educ. 2014, 79, 49-58. [CrossRef]

40. Lorenzo, G.; Lledó, A.; Pomares, J.; Roig, R. Design and application of an immersive virtual reality system to enhance emotional skills for children with autism spectrum disorders. Comput. Educ. 2016, 98, 192-205. [CrossRef]

41. Martirosov, S.; Bureš, M.; Zítka, T. Cyber sickness in low-immersive, semi-immersive, and fully immersive virtual reality. Virtual Real. 2021, 1-18. [CrossRef]

42. Cheung, K.L.; Tunik, E.; Adamovich, S.V.; Boyd, L.A. Neuroplasticity and virtual reality. In Virtual Reality for Physical and Motor Rehabilitation; Weiss, P., Keshner, E., Levin, M., Eds.; Springer: New York, NY, USA, 2014; pp. 5-24.

43. Coco-Martin, M.B.; Piñero, D.P.; Leal-Vega, L.; Hernández-Rodríguez, C.J.; Adiego, J.; Molina-Martín, A.; de Fez, D.; Arenillas, J.F The potential of virtual reality for inducing neuroplasticity in children with amblyopia. J. Ophthalmol. 2020, 2020, 1-9. [CrossRef]

44. Calvert, J.; Abadia, R. Impact of immersing university and high school students in educational linear narratives using virtual reality technology. Comput. Educ. 2020, 159, 104005. [CrossRef]

45. Ye, X.; Liu, P.-F.; Lee, X.-Z.; Zhang, Y.-Q.; Chiu, C.-K. Classroom misbehaviour management: An SVVR-based training system for preservice teachers. Interact. Learn. Environ. 2021, 29, 112-129. [CrossRef]

46. Sun, F.-R.; Pan, L.-F.; Wan, R.-G.; Li, H.; Wu, S.-J. Detecting the effect of student engagement in an SVVR school-based course on higher level competence development in elementary schools by SEM. Interact. Learn. Environ. 2021, 29, 3-16. [CrossRef]

47. Lee, S.H.; Sergueeva, K.; Catangui, M.; Kandaurova, M. Assessing Google Cardboard virtual reality as a content delivery system in business classrooms. J. Educ. Bus. 2017, 92, 153-160. [CrossRef]

48. Chang, S.-C.; Hsu, T.-C.; Chen, Y.-N.; Jong, M.S.-Y. The effects of spherical video-based virtual reality implementation on students' natural science learning effectiveness. Interact. Learn. Environ. 2020, 28, 915-929. [CrossRef]

49. Wu, J.; Guo, R.; Wang, Z.; Zeng, R. Integrating spherical video-based virtual reality into elementary school students' scientific inquiry instruction: Effects on their problem-solving performance. Interact. Learn. Environ. 2021, 29, 496-509. [CrossRef]

50. Jong, M.S.-Y.; Tsai, C.-C.; Xie, H.; Wong, F.K.-K. Integrating interactive learner-immersed video-based virtual reality into learning and teaching of physical geography. Br. J. Educ. Technol. 2020, 51, 2064-2079. [CrossRef]

51. Ulrich, F.; Helms, N.H.; Frandsen, U.P.; Rafn, A.V. Learning effectiveness of $360^{\circ}$ video: Experiences from a controlled experiment in healthcare education. Interact. Learn. Environ. 2021, 29, 98-111. [CrossRef]

52. Kittel, A.; Larkin, P.; Elsworthy, N.; Spittle, M. Using 360 degrees virtual reality as a decision-making assessment tool in sport. J. Sci. Med. Sport 2019, 22, 1049-1053. [CrossRef]

53. Alpala, D.P.O.; Peña, N.M. A virtual room to enhance writing skills in the EFL class. HOW 2014, 21, 62-81. [CrossRef]

54. Xu, Y.; Park, H.; Baek, Y. A new approach toward digital storytelling: An activity focused on writing self-efficacy in a virtual learning environment. J. Educ. Techno. Soc. 2011, 14, 181-191.

55. Chen, M.-R.A.; Hwang, G.-J. Effects of experiencing authentic contexts on English speaking performances, anxiety and motivation of EFL students with different cognitive styles. Interact. Learn. Environ. 2020, 1-21. [CrossRef]

56. Chien, S.-Y.; Hwang, G.-J.; Jong, M.S.-Y. Effects of peer assessment within the context of spherical video-based virtual reality on EFL students' English-speaking performance and learning perceptions. Comput. Educ. 2020, 146, 103751. [CrossRef]

57. Dolgunsöz, E.; Yildirim, G.; Yildirim, S. The effect of virtual reality on EFL writing performance. J. Lang. Linguist. Stud. 2018, 14, 278-292.

58. Walshe, N.; Driver, P. Developing reflective trainee teacher practice with 360-degree video. Teach. Teach. Educ. 2019, 78, 97-105. [CrossRef]

59. Di Serio, Á.; Ibáñez, M.B.; Kloos, C.D. Impact of an augmented reality system on students' motivation for a visual art course. Comput. Educ. 2013, 68, 586-596. [CrossRef]

60. Dunn, T.J.; Kennedy, M. Technology enhanced learning in higher education; motivations, engagement and academic achievement. Comput. Educ. 2019, 137, 104-113. [CrossRef]

61. Cheung, W.M.; Tse, S.K.; Tsang, W.H.H. Development and validation of the Chinese creative writing scale for primary school students in Hong Kong. J. Creat. Behav. 2001, 35, 249-260. [CrossRef]

62. Yeung, P.-S.; Ho, C.S.-H.; Chan, D.W.-O.; Chung, K.K.-H. Writing motivation and performance in Chinese children. Read. Writ. 2020, 33, 427-449. [CrossRef]

63. Suriyanti, S.; Yaacob, A. Exploring teacher strategies in teaching descriptive writing in Indonesia. Malays. J. Learn. Instr. 2016, 13, 71-95. [CrossRef]

64. Skinner, E.; Furrer, C.; Marchand, G.; Kindermann, T. Engagement and disaffection in the classroom: Part of a larger motivational dynamic? J. Educ. Psychol. 2008, 100, 765-781. [CrossRef]

65. Cohen, J. Statistical Power Analysis for the Behavioral Sciences, 2nd ed.; Routledge Academic: New York, NY, USA, 1988.

66. Styati, E.W. Effect of YouTube videos and pictures on EFL students' writing performance. Din. Ilmu 2016, 16, 307-317. [CrossRef]

67. Paas, F.; Renkl, A.; Sweller, J. Cognitive load theory and instructional design: Recent developments. Educ. Psychol. 2003, 38, 1-4. [CrossRef]

68. Gibbs, R.W.; Leggitt, J.S.; Turner, E.A. What's special about figurative language in emotional communication? In The Verbal Communication of Emotions: Interdisciplinary Perspectives; Fussell, S.R., Ed.; Lawrence Erlbaum: Mahwah, NJ, USA, 2002; pp. $125-149$. 
69. Newmann, F.M.; Wehlage, G.G.; Lamborn, S.D. The significance and sources of student engagement. In Student Engagement and Achievement in American Secondary Schools; Newmann, F.M., Ed.; Teachers College Press: New York, NY, USA, 1992 ; pp. 11-39.

70. Appleton, J.J.; Christenson, S.L.; Furlong, M.J. Student engagement with school: Critical conceptual and methodological issues of the construct. Psychol. Sch. 2008, 45, 369-386. [CrossRef]

71. Baron, P.; Corbin, L. Student engagement: Rhetoric and reality. High. Educ. Res. Dev. 2012, 31, 759-772. [CrossRef]

72. Finn, J.D. School Engagement and Students at Risk; National Center for Education Statistics: Washington, DC, USA, 1993.

73. Marks, H.M. Student engagement in instructional activity: Patterns in the elementary, middle, and high school years. Am. Educ. Res. J. 2000, 37, 153-184. [CrossRef]

74. Van Waes, L.; van Weijen, D.; Leijten, M. Learning to write in an online writing center: The effect of learning styles on the writing process. Comput. Educ. 2014, 73, 60-71. [CrossRef] 